\title{
O EXCESSO DE CORRESPONDÊNCIA: UM EXPERIMENTO COM AUDITORES NO CONTEXTO BRASILEIRO
}

\author{
Michel Cohen 1 \\ Marcos Gonçalves Avila 2
}

- Artigo recebido em: 25/09/2015 -• Artigo aceito em: 13/07/2018 -- Segunda versão aceita em: 29/07/2018

\begin{abstract}
RESUMO
Um experimento foi conduzido a partir do plano de referência conceitual associado à teoria da inferência correspondente. Especificamente, o interesse deste trabalho foi $o$ de investigar a existência do viés de julgamento denominado excesso de correspondência. Esse viés se refere à tendência das pessoas de, ao tentarem explicar as causas para o comportamento que observam em outras pessoas, superestimar a influência de causas internas (características pessoais) e subestimar a influência de causas externas (fatores situacionais). No experimento, os participantes (auditores do Tribunal de Contas da União - TCU) foram instruídos a estimar a posição real de um gestor fictício a respeito do tema Regime Diferenciado de Contratações Públicas (RDC), depois de ler um texto escrito pelo gestor, onde ele expressava opinião a respeito do tópico. As variáveis independentes do estudo foram posição do texto (favorável ou contrária ao RDC) e contexto, isto é, liberdade de escolha por parte do gestor quanto à posição a ser assumida no texto (com liberdade de escolha ou sem liberdade de escolha). Os participantes do experimento foram informados previamente à leitura do texto escrito pelo gestor sobre o contexto em que o texto havia sido preparado. A hipótese principal de pesquisa (confirmada no experimento) foi de que os auditores incorreriam no excesso de correspondência, isto é, eles julgariam a posição real do gestor em relação ao tema em função da posição descrita no texto, independente do gestor ter tido escolha em expressar àquela posição.
\end{abstract}

Palavras-chave: Excesso de correspondência, viés de correspondência, erro fundamental de atribuição.

\section{THE CORRESPONDENCE EXCESS: AN EXPERIMENT WITH AUDITORS IN THE BRAZILIAN CONTEXT}

\footnotetext{
1 Auditor Federal de Controle Externo, TCU.

2 Professor Associado (Aposentado). Instituto COPPEAD de Administração/Universidade Federal do Rio de Janeiro. Endereço: Rua Pacheco Leão 646, Casa 14 - Jardim Botânico. 22460-030, Rio de janeiro Brasil. Telefone: (21)99915-8568. e-mail: marcos@coppead.ufrj.br.
} 


\section{ABSTRACT}

An experiment was conducted within the framework of correspondent inference theory. Specifically, this study investigated the existence of a judgmental bias called the correspondence excess. This bias refers to people's tendency to explain other people's behavior by overestimating the influence of internal factors (personal traits) and underestimating the influence of external (situational) factors. The subjects of the experiment, auditors of the Brazilian Federal Court of Accounts - TCU, were instructed to estimate the true position of a fictitious manager regarding the theme Regime Diferenciado de Contratações Públicas RDC (an exceptional and differentiated framework for public contracting processes), after having read a text written by him, expressing opinions on this topic. The study's independent variables included position of the text (pro or anti) and choice of position (free to choose or previously assigned). The subjects were previously informed about the context in which the text was constructed (ie, freedom, or not, to choose the position described in the text). The major hypothesis (which was confirmed in the experiment) was that the subject's experimental behavior would be consistent with the correspondence bias, that is, they would estimate the true position of the manager on the topic in function of the position expressed in the text, regardless of whether the manager had a choice in expressing that position.

Keywords: Correspondence excess, correspondence bias, the fundamental attribution error.

\section{INTRODUÇÃO}

Quando alguém emite uma opinião, pode ser difícil avaliar se a opinião corresponde ao que a pessoa de fato acredita. A opinião pode refletir influências do contexto (fatores externos) e não necessariamente a visão pessoal ou traços de personalidade (fatores internos). A literatura de psicologia social sugere que tendemos a ignorar, ou subestimar, a influência de causas externas (contexto) e superestimar a influência de causas internas (características da pessoa). Esse fenômeno é denominado viés de correspondência ou simplesmente excesso de correspondência (JONES; HARRIS, 1967). Esta última expressão será adotada no restante deste texto.

Este trabalho apresenta os resultados de um experimento conduzido para testar a existência do excesso de correspondência. O experimento foi realizado tendo como sujeitos da pesquisa, auditores do Tribunal de Contas da União. No âmbito da atividade de fiscalização, os auditores analisam resultados que são decorrentes do comportamento dos gestores envolvidos na geração daqueles resultados. O comportamento decorre de uma combinação de fatores internos (características dos gestores, isto é, perícia, valores morais e capacidade técnica) com fatores situacionais (o ambiente da empresa em que o gestor desenvolve suas atividades, as normas existentes, e pressão dos superiores). Ao atribuir causas aos comportamentos observados, os auditores precisam estar atentos a todos os fatores. Em outras palavras, a atividade de auditoria demanda uma capacidade de atribuição causal apurada. 
A relevância deste estudo está associada à inexistência de investigações sobre o excesso de correspondência na atividade de auditoria. Auditores têm que lidar com a tarefa de formular opiniões sobre a conduta de diversos agentes e nesse processo fazer, com frequência, atribuições de natureza causal em relação aos atos praticados por gestores. Assim, é importante a identificação da ocorrência, em potencial, de vieses de julgamento que possam contribuir para a redução na habilidade de formular julgamentos apropriados sobre as situações sendo examinadas. Shanteau (1989) indica que até o início da década de 90, havia pelo menos 40 estudos sobre heurísticas e vieses na literatura de contabilidade e auditoria. Não se constatou à época, e não se constatam até hoje, no entanto, estudos envolvendo auditores e o excesso de correspondência. Até onde podemos investigar, os experimentos conduzidos sobre o tema, todos no ambiente internacional, tem usado somente estudantes de graduação como sujeitos.

\section{REVISÃO DE LITERATURA}

\subsection{Teoria da Atribuição: Conceito Geral}

A expressão Teoria da Atribuição se refere ao arcabouço teórico da psicologia social que busca a compreensão sobre como as pessoas tentam entender as causas e implicações dos eventos que observam (ROSS e ANDERSON, 1982). Hogg e Vaughan (2011) sugerem que o pensamento humano está preocupado em buscar, construir e testar explicações sobre nossas experiências. Tentamos entender nosso mundo de forma a deixá-lo ordenado e com significado, e tendemos a nos sentir desconfortáveis se não julgarmos que temos este entendimento. Explicações causais são particularmente poderosas como bases de atividades de previsão e controle.

\subsection{Teorias normativas sobre atribuição}

As principais teorias normativas sobre atribuição de causalidade incluem, segundo Hogg e Vaughan (2011) e Ross e Anderson (1982), a teoria do psicólogo intuitivo de Heider (1958), a teoria da inferência correspondente de Jones e Davis (1965) e a teoria da covariação de Kelley (1967).

A necessidade de as pessoas obterem explicações causais para o que observam fica evidenciada, segundo Heider (1958), pelo fato de que quase todas as sociedades construíram um mito original, uma elaborada explicação causal para a origem e significado da vida (que em geral é o elemento central de uma religião). Esse autor articula a proposta de que ao atribuir causalidade ao comportamento observado, distinguimos entre fatores pessoais (personalidade, habilidade) e fatores ambientais (situações, pressões sociais). Fatores situacionais, ou externos representam essencialmente as circunstâncias em que nos encontramos num determinado momento. Podem ser fatores físicos (temperatura do ar, ruído, cores, etc.), fatores sociais (fatores relacionados com a presença real ou implícita de outras pessoas) ou mesmo fatores indeterminados, aleatórios. Fatores internos representam os fatores que têm a ver com traços de personalidade, humor, atitudes, capacidade, habilidade e esforço (HEIDER, 1958). 
A partir do trabalho de Heider (1958), Jones e Davis (1965) desenvolveram a denominada teoria da inferência correspondente. A palavra correspondente tem um significado específico na teoria: "Quando uma pessoa verbaliza uma opinião ela pode ou não ter uma atitude subjacente que "corresponde" àquela opinião. O grau em que opiniões e atitudes são vistos como correspondentes é descrito como função do peso relativo associado a fatores causais internos versus fatores causais externos" (JONES e HARRIS, 1967, p.1). Por exemplo, se uma opinião for expressa sem qualquer pressão situacional, o julgamento tenderá a ser de que essa pessoa tem atitudes que correspondem às opiniões declaradas.

A teoria de Jones e Harris (1967) é de que pode-se falar em um maior ou menor grau de inferência correspondente para descrever a inferência por parte de um observador sobre o grau em que determinada pessoa de fato acredita na opinião que emite. A correspondência (entre a opinião emitida pelo Sr. X e a crença do Sr. X nessa opinião) será, segundo esses autores, alta quando a opinião foi emitida por livre e espontânea vontade e a probabilidade de se observar aquela opinião em outros indivíduos é baixa, ou seja, não se trata de uma opinião que pessoas manifestam apenas por conveniência.

Kelley (1967) articulou a teoria normativa de atribuição conhecida como - modelo de covariação. A teoria descreve as pessoas como "cientistas intuitivos tentando inferir causas para os efeitos que observa" (NISBET et al, 1982, p. 101). De acordo com Kelley, as atribuições causais são baseadas em julgamentos sobre covariância, ou seja, um efeito é atribuído a uma de suas possíveis causas se, ao longo do tempo, esse efeito e a causa covariam (estão correlacionados). As pessoas usam, segundo o autor, esse princípio da covariação para decidir se atribuem o comportamento a disposições internas (personalidade) ou a fatores ambientais externos (pressão social).

Outras teorias sobre atribuição, ou extensões de teorias existentes, incluem a teoria da fragilidade emocional de Schachter (1964), a teoria da autopercepção de Bem (1967) e a teoria atribucional de Weiner $(1979,1985)$.

\subsection{Vieses em atribuição: $O$ excesso de correspondência}

Uma extensa literatura tem investigado a capacidade preditiva das teorias normativas de atribuição (TETLOCK, 1985, HILL, 2001, HOGG e VAUGHAN, 2011). Um dos vieses que tem sido identificado no processo de atribuições causais se refere à tendência das pessoas em atribuir de forma excessiva causas internas, estáveis e subjacentes da personalidade, a comportamentos que poderiam (deveriam) ser explicados por fatores situacionais. (GILBERT e MALONE, 1995). Ross, Amabile e Steinmetz (1977) argumentam que essa tendência, excessiva, de explicar comportamentos em termos de disposições pessoais é disseminada e universal. Esse viés é denominado excesso de correspondência (GILBERT E MALONE, 1965; JONES E HARRIS, 1967). Ross, Amabile e Steinmetz (1977) cunharam a expressão Erro Fundamental de Atribuição para se referir a ele. 


\subsection{Evidências empíricas do excesso de correspondência}

Jones e Harris (1967) desenvolveram o método de atribuição de atitudes para investigar o excesso de correspondência. Este método será adotado neste trabalho. Nesse paradigma experimental, os participantes são instados a inferir sobre a posição real de um fictício autor (ou seja, inferir sobre o que ele realmente acredita) em relação a um tópico específico (por exemplo, aborto, legalização da maconha, etc.). Para essa tarefa de julgamento, os participantes recebem um texto sobre o tópico em questão, escrito pelo autor cuja posição real será julgada. Numa condição - descrita como a condição de liberdade de escolha - os participantes são informados de que o autor estava livre para escolher a posição que quisesse defender no texto (pró ou contra). Na segunda condição - descrita como a condição restrita ou sem escolha - os participantes são informados de que foram designadas posições a serem defendidas pelos autores.

Os participantes cometem o excesso de correspondência ao inferirem uma posição por parte do autor (isto é, que o autor acredita em algo) a partir da inclinação do texto (pró ou contra), sem levar em consideração se os autores tiveram escolha em relação a opinião expressa no texto. $O$ excesso de correspondência foi caracterizado (e chamado à época de viés do observador) no experimento conduzido por Jones e Harris (1967). Neste clássico experimento foram mostrados aos participantes textos que apoiavam ou criticavam o presidente de Cuba, Fidel Castro. Os sujeitos do experimento foram divididos em dois grupos. Os pesquisadores informavam aos participantes do primeiro grupo que o autor do texto tinha tido liberdade para determinar a posição que iria apoiar, e informavam aos participantes do segundo grupo que o autor do texto tinha sido instruído a apoiar um determinado ponto de vista (pró-Castro ou anti-Castro).

Conforme esperado, de acordo com a teoria da inferência correspondente, os participantes do primeiro grupo (grupo com liberdade de escolha) inferiram corretamente o posicionamento dos autores (suas reais posições), em relação ao tema, fortemente pró ou anti, a partir da leitura dos textos recebidos. Ao contrário do esperado por Jones e Harris (1967), entretanto, os participantes do segundo grupo (grupo sem liberdade de escolha) fizeram inferências similares sobre o autor do texto, mesmo sabendo que o autor havia sido instruído a escrever um texto com determinada inclinação (pró-Castro ou anti-Castro). Em suma, observou-se que os participantes inferiram correspondências internas do autor (associaram a posição do texto a aspectos pessoais do autor), mesmo no cenário em que o autor não havia vivenciado liberdade para escolher a inclinação do texto.

Essa tendência de independente do contexto inferir que existe uma correspondência entre a posição real e a posição manifestada no texto é um achado robusto. Essa inferência tem mostrado independer das posições pessoais dos participantes dos experimentos (ALICKE, ZERBST e LOSCHIAVO, 1996), da ordem entre o texto lido pelo participante e a informação de que o autor do texto estava numa situação de escolha ou de não escolha em relação à posição do texto (JONES, RIGGS e QUATTRONE, 1979), da inclusão de avisos explícitos sobre as possibilidades de existirem vieses de julgamento (CROXTON e MILLER, 1987), de textos autênticos ou artificiais (SNYDER e JONES, 1974), de 
informações adicionais sobre o autor do texto (MILLER, 1976) e até mesmo de diferenças culturais (CHOI e NISBETT, 1998).

Estudos posteriores replicaram o estudo original de Jones e Harris (1967) e apresentaram resultados consistentes com os desses autores. Esses estudos aplicaram a abordagem de atribuição de atitudes, modificando o conteúdo dos textos e acrescentando algumas variáveis, como a responsabilidade dos participantes em seus julgamentos, a extremidade da argumentação e a medida prévia da posição dos participantes em relação ao tema, e a padronização ou não da argumentação dos textos (TETLOCK, 1985, SNYDER e JONES, 1974).

Cabe ressaltar, entretanto, que os estudos experimentais internacionais que investigaram o excesso de correspondência envolveram estudantes de graduação. A proposta da presente pesquisa é realizar um experimento com base no paradigma da atribuição de atitudes no contexto do Brasil e contando com auditores profissionais do Tribunal de Contas da União como sujeitos da pesquisa.

\section{EXPERIMENTO}

\subsection{Descrição do experimento}

Este experimento tem como referência o experimento desenvolvido por Jones e Harris (1967) e replicado ulteriormente em diversos outros estudos, com modificações no desenho experimental e adições de variáveis independentes (MILLER e RORER, 1982, TETLOCK, 1985, SNYDER e JONES, 1974, JONES, 1979, MILLER et al, 1984, MILLER, 1976).

A pergunta geral de pesquisa: Em uma situação em que os auditores sejam instados a avaliar a real posição de um gestor público a respeito de uma determinada questão, até que ponto o julgamento dos auditores será caracterizado pelo excesso de correspondência?

Neste experimento os participantes (auditores) foram instruídos a estimar a real posição de um gestor fictício a respeito de determinada questão. Especificamente, a inferência foi solicitada em seguida a leitura de um texto (as instruções do experimento afirmavam que o texto havia sido escrito pelo gestor) com uma posição a favor ou contra o tema do Regime Diferenciado de Contratações Públicas - RDC. Este tema é afeto às atribuições do grupo de auditores do Tribunal de Contas da União, uma vez que versa sobre legislação que foi implementada recentemente, estabelecendo condições diferenciadas para licitações e contratos cujo propósito seja construir a infraestrutura necessária à realização da Copa do Mundo no Brasil em 2014 e das Olimpíadas no Rio de Janeiro em 2016 (o experimento foi conduzido em 2013)

Todos os auditores foram informados previamente à leitura do texto escrito pelo gestor sobre as condições (o contexto) em que aquele texto fora preparado. Especificamente, era especificado se o gestor havia vivenciado, ou não, liberdade de escolha quanto à posição a ser assumida no texto. Após a leitura do texto, o auditor era instado a inferir, conforme escala disponibilizada, a 
real posição do gestor em relação ao tema (as condições experimentais são detalhadas no Apêndice a este trabalho).

O experimento contou, portanto, com um desenho fatorial $2 \times 2$. onde as variáveis independentes foram liberdade de escolha (com/sem) e posição do texto (contra / a favor do tema do RDC). A variável dependente foi a medida de avaliação por parte dos sujeitos da pesquisa (os auditores) da real posição do gestor sobre o tema. A definição operacional das variáveis independentes e da variável dependente será descrita a seguir.

\subsubsection{Variáveis independentes}

Todas as condições experimentais tinham o mesmo texto introdutório:

Considere o contexto abaixo sobre o então projeto que resultou na lei 12.462/2011, que instituiu o Regime Diferenciado de Contratações Públicas RDC, aplicável exclusivamente às licitações e contratos necessários à realização dos Jogos Olímpicos, da Copa das Confederações e da Copa do Mundo (e de obras de infraestrutura e serviços em aeroportos em alguns casos).

Em cada condição experimental era então descrito o contexto (com ou sem liberdade de escolha) e o texto preparado pelo gestor (a favor ou contra a proposta do Regime Diferenciado De Contratações Públicas - RDC). As quatro condições experimentais:

\section{Gestor sem liberdade de escolha e texto com posição favorável ao RDC:}

Contexto - Imagine que um dirigente público convocou aleatoriamente diversos gestores, também públicos, para discutir de maneira abrangente prós e contras do Regime Diferenciado de Contratações Públicas - RDC, enquanto era ainda uma proposta de lei. Imagine que não houve consenso no debate. $O$ dirigente público, então, determinou que um dos gestores, escolhido por sorteio, escrevesse um pequeno texto com os principais pontos a favor, que caracterizassem uma contundente defesa do RDC. O texto serviria de subsídio para um debate que terminaria no Senado Federal.

Texto indicado como tendo sido preparado pelo gestor: O RDC propiciará inúmeras vantagens à Administração Pública. Ao se evitar algumas das prescrições burocráticas da lei 8.666/93, será assegurada maior rapidez ao processo licitatório, permitindo, dessa forma, condições realmente vantajosas para a Administração Pública. A urgência no estabelecimento de novas regras para a Copa do Mundo e Olimpíadas justifica uma legislação específica, tal qual o RDC, pois não há tempo hábil para tramitação de uma nova legislação geral sobre licitações e contratos. Os prejuízos de não conseguir sediar tais eventos, por causa da falta de legislação célere, seriam incalculáveis. A imagem do país junto à comunidade internacional ficaria bastante prejudicada. Com relação à questão sobre a constitucionalidade do RDC, considera-se que é um mero detalhe formal, passível de ser sanado no Congresso Nacional, com a aprovação devida.

\section{Gestor sem liberdade de escolha e texto com posição contrária ao RDC:}

Contexto: Imagine que um dirigente público convocou aleatoriamente diversos gestores, também públicos, para discutir de maneira abrangente prós e contras do Regime Diferenciado de Contratações Públicas - RDC, enquanto era 
ainda uma proposta de lei. Imagine que não houve consenso no debate. 0 dirigente público, então, determinou que um dos gestores, escolhido por sorteio, escrevesse um pequeno texto com os principais pontos contra que caracterizassem uma contundente crítica ao RDC. O texto serviria de subsídio para um debate que terminaria no Senado Federal.

Texto: $O$ RDC somente propiciará desvantagens à Administração Pública. Mesmo ao se evitar somente algumas das prescrições da lei 8.666/93, haverá um atropelamento de passos necessários do processo licitatório, impedindo, dessa forma, condições realmente vantajosas para a Administração Pública. A urgência no estabelecimento de novas regras para a Copa do Mundo e Olimpíadas não justifica uma legislação específica, tal qual o RDC, pois há tempo hábil para tramitação de uma nova legislação geral sobre licitações e contratos. Os prejuízos em virtude de desvios decorrentes da não aplicação das regras da lei 8.666/93, nos pontos em que o RDC modificará o processo, seriam incalculáveis. A Administração Pública ficaria mais suscetível a pagar preços superfaturados. Existe, ainda, a questão sobre a inconstitucionalidade do RDC, nos termos em que está sendo proposto no Congresso Nacional, aspecto esse que não é uma mera formalidade.

\section{Gestor com liberdade de escolha e texto com posição favorável ao RDC:}

Contexto: Imagine que um dirigente público convocou aleatoriamente diversos gestores, também públicos, para discutir de maneira abrangente prós e contras do Regime Diferenciado de Contratações Públicas - RDC, enquanto era ainda uma proposta de lei. Imagine que não houve consenso no debate. 0 dirigente público, então, determinou que um dos gestores, escolhido por sorteio, escrevesse um pequeno texto com os principais pontos, defendendo ou criticando o RDC, conforme a opinião do gestor. O texto serviria de subsídio para um debate que terminaria no Senado Federal.

Texto: $O$ RDC propiciará inúmeras vantagens à Administração Pública. Ao se evitar algumas das prescrições burocráticas da lei 8.666/93, será assegurada maior rapidez ao processo licitatório, permitindo, dessa forma, condições realmente vantajosas para a Administração Pública. A urgência no estabelecimento de novas regras para a Copa do Mundo e Olimpíadas justifica uma legislação específica, tal qual o RDC, pois não há tempo hábil para tramitação de uma nova legislação geral sobre licitações e contratos. Os prejuízos de não conseguir sediar tais eventos, por causa da falta de legislação célere, seriam incalculáveis. A imagem do país junto à comunidade internacional ficaria bastante prejudicada. Com relação à questão sobre a constitucionalidade do RDC, considera-se que é um mero detalhe formal, passível de ser sanado no Congresso Nacional, com a aprovação devida.

\section{Gestor com liberdade de escolha e texto com posição contrária ao RDC:}

Contexto: Imagine que um dirigente público convocou aleatoriamente diversos gestores, também públicos, para discutir de maneira abrangente prós e contras do Regime Diferenciado de Contratações Públicas - RDC, enquanto era ainda uma proposta de lei. Imagine que não houve consenso no debate. 0 dirigente público, então, determinou que um dos gestores, escolhido por sorteio, escrevesse um pequeno texto com os principais pontos, defendendo ou 
criticando o RDC, conforme a opinião do gestor. O texto serviria de subsídio para um debate que terminaria no Senado Federal.

Texto: $O$ RDC somente propiciará desvantagens à Administração Pública. Mesmo ao se evitar somente algumas das prescrições da lei 8.666/93, haverá um atropelamento de passos necessários do processo licitatório, impedindo, dessa forma, condições realmente vantajosas para a Administração Pública. A urgência no estabelecimento de novas regras para a Copa do Mundo e Olimpíadas não justifica uma legislação específica, tal qual o RDC, pois há tempo hábil para tramitação de uma nova legislação geral sobre licitações e contratos. Os prejuízos em virtude de desvios decorrentes da não aplicação das regras da lei 8.666/93, nos pontos em que o RDC modificará o processo, seriam incalculáveis. A Administração Pública ficaria mais suscetível a pagar preços superfaturados. Existe, ainda, a questão sobre a inconstitucionalidade do RDC, nos termos em que está sendo proposto no Congresso Nacional, aspecto esse que não é uma mera formalidade.

\subsubsection{Variável dependente}

A medida de avaliação da real posição do gestor sobre o tema do RDC foi operacionalmente definida através de um conjunto de 10 afirmações. As cinco primeiras afirmações eram consistentes com uma posição a favor do tema do RDC ao passo que as cinco afirmações seguintes refletiam posições contrárias ao tema do RDC. Cada auditor foi solicitado a emitir julgamento sobre grau em que o gestor discordava ou concordava com cada afirmação, em uma escala de 1 (discordava totalmente) a 7 (concordava totalmente). 0 ponto central da escala (número 4) era explicitado como 'Nem concorda nem discorda'. Os auditores que inferissem, por exemplo, que a real posição do gestor era totalmente a favor do tema, em todos os itens avaliados, marcariam a escala na extremidade próxima a 7 nas cinco primeiras afirmações, e na extremidade próxima a 1 nas cinco afirmações finais. A pontuação atribuída em cada uma das cinco últimas afirmações foi invertida, de modo que quem marcasse 1 somasse 7 pontos, quem marcasse 2 somasse 6 pontos, e assim por diante. Em consequência, a pontuação máxima (pró RDC) era de 70 pontos e a pontuação mínima (contra RDC) era de 10 pontos. Esta estrutura de construção da pontuação associada às afirmações foi similar a escala usada por Jones e Harris (1967). Os auditores indicaram em seguida, para o mesmo conjunto de afirmações, e na mesma escala de 1 a 7, o grau em que eles próprios concordavam com cada item exposto. O propósito deste segundo questionário foi observar se haveria diferença estatisticamente significante entre os grupos de auditores em cada uma das quatro condições.

Relação das 10 afirmações, na ordem em que foram apresentadas:

- O setor público precisa cada vez mais de uma legislação que desburocratize e agilize o processo licitatório.

- A Copa do Mundo e as Olimpíadas trarão muito retorno ao país, devendo ser tomadas medidas excepcionais,

- É preciso evitar que discussões sobre formalidades impeçam a realização de eventos como a Copa do Mundo e as Olimpíadas. 
- O tipo de lei de licitações e contratos não faz diminuir ou aumentar consideravelmente os desvios de recursos, mas sim a atitude ética ou não dos gestores e pessoas envolvidas nas licitações e contratos.

- Para que seja cumprido o princípio constitucional da eficiência, faz-se necessária a existência de uma legislação ágil e eficaz no que diz respeito às licitações e aos contratos.

- Nenhum evento - seja a Copa do Mundo, sejam as Olimpíadas - pode servir de justificativa para que se atropele as formalidades requeridas pelo processo legislativo, uma vez que este existe devido à vontade do povo.

- Existem muitos assuntos mais urgentes do que a realização de obras para a Copa do Mundo e para as Olimpíadas, de modo que não se justifica um regime diferenciado na realização de obras para esses eventos.

- Para que sejam cumpridos os princípios da economicidade, é imprescindível que sejam cumpridas as regras da lei geral de licitações (Lei 8.666/93), não podendo legis/ação específica modificar suas regras básicas.

\subsection{Hipóteses}

Se o gestor se manifesta, livremente, a favor (contra) do RDC, espera-se que os participantes do experimento (os auditores) considerem que esse gestor se posiciona a favor (contra) o RDC. Portanto, a hipótese inicial de pesquisa pode ser descrita como se segue:

$\mathrm{H}_{1}$ : A média das avaliações da posição do gestor sobre o tema do RDC na condição experimental com liberdade de escolha e texto favorável ao RDC será significativamente maior do que a média das avaliações na condição com liberdade de escolha e texto contrário ao RDC.

A segunda, e principal, hipótese de pesquisa do trabalho considera que os auditores julgarão a atitude do gestor em relação ao tema apresentado incorrendo no excesso de correspondência. A hipótese é de que mesmo na ausência de liberdade de escolha quanto a posição a ser assumida pelo gestor na preparação do texto, os auditores julgarão a posição real dos gestores em relação ao tema apresentado em função da posição assumida no texto. Ou seja:

$\mathrm{H}_{2}$ : A média das avaliações da posição do gestor na condição sem liberdade de escolha e texto favorável ao RDC será significativamente maior do que a média das avaliações na condição sem liberdade de escolha e texto contrário ao RDC.

Duas hipóteses complementares foram testadas. Em primeiro lugar, nos casos em que o texto preparado pelo gestor seja a favor do RDC, é de se esperar que na condição de liberdade de escolha os auditores julguem existir uma maior correspondência entre a posição do texto e a posição real do gestor do que julgarão existir na condição sem liberdade de escolha. Pode ser, entretanto, que o excesso de correspondência seja forte o suficiente para que essa diferença não seja significativa. Esta alternativa se traduz na seguinte hipótese de pesquisa:

10 Revista Contabilidade Vista \& Revista, ISSN 0103-734X, Universidade Federal de Minas Gerais, Belo Horizonte, v. 29, n. 2, p. 01-17, mai./ago. 2018 
$\mathrm{H}_{3}$ : A média das avaliações da posição do gestor na condição com liberdade de escolha e texto favorável ao RDC não será estatisticamente diferente da média das avaliações na condição sem liberdade de escolha e texto favorável ao RDC.

A hipótese final de pesquisa refere-se a uma expectativa similar, nos cenários em que o texto for contra o tema do RDC.

$\mathrm{H}_{4}$ : A média das avaliações da posição do gestor na condição com liberdade de escolha e texto contrário ao RDC não será estatisticamente diferente da média das avaliações na condição sem liberdade de escolha e texto contrário ao RDC.

\subsection{Coleta de dados e amostra}

O estudo coletou os dados por meio da aplicação de um questionário online, com as quatro condições experimentais. Cada participante foi aleatoriamente encaminhado para cada uma das versões.

Os participantes foram convidados por meio de um texto padrão, encaminhado por meio eletrônico, isto é, e-mail ou jornal interno do Tribunal de Contas da União. O texto indicava o link para a participação na pesquisa e esclarecia alguns dados básicos do experimento, sem explicação sobre as hipóteses. Antes da divulgação online do experimento, foi realizado um préteste com quatro auditores, que foram solicitados a responder e revelar o que haviam entendido das perguntas e esclarecer suas eventuais dúvidas. De acordo com as avaliações e comentários dos respondentes foram incorporados os ajustes necessários, permitindo a formatação final da instrução experimental, do contexto, do texto e dos questionários. Participaram do experimento 85 auditores.

\section{RESULTADOS E ANÁLISE}

A Tabela 1 apresenta as médias das estimativas feitas pelos participantes em relação à real posição dos gestores em cada uma das quatro condições experimentais. A observação dos números da Tabela 1 permite que se extraia imediatamente uma conclusão geral sobre os resultados: a posição expressa no texto impactou a avaliação dos auditores sobre a real posição dos gestores, independentemente de o gestor ter tido liberdade de escolha quanto à posição que foi assumida na redação do texto.

Tabela 1: Médias das estimativas dos auditores quanto à real posição do gestor sobre o tema do RDC

\begin{tabular}{|c|c|c|}
\hline \multirow{2}{*}{ Contexto } & \multicolumn{3}{|c|}{ Posição do texto } \\
\cline { 2 - 3 } & $\begin{array}{c}\text { Texto favorável ao } \\
\text { RDC }\end{array}$ & $\begin{array}{c}\text { Texto contrário ao } \\
\text { RDC }\end{array}$ \\
\hline $\begin{array}{c}\text { Gestor sem liberdade de } \\
\text { escolha }\end{array}$ & $53,63 \quad(n=16)$ & $28,77 \quad(n=22)$ \\
\hline $\begin{array}{c}\text { Gestor com liberdade de } \\
\text { escolha }\end{array}$ & $54,50 \quad(n=24)$ & $28,17 \quad(n=23)$ \\
\hline
\end{tabular}

Fonte: Elaborada pelos autores 
Para efeito de comparações entre as médias, foram usados o teste † e o teste da soma dos postos de Wilcoxon. A comparação da condição com liberdade de escolha / texto favorável ao RDC com a condição com liberdade de escolha / texto contrário ao RDC $(54,50$ vs 28,$17 ; t=11,10 ; p<0,01$; Wilcoxon, $p$ $<0,01$ ) indica uma diferença estatisticamente significante entre as médias. Este resultado mostra que os auditores foram consistentes na avaliação, no cenário de liberdade de escolha. Como o gestor estava livre para decidir sobre que posição adotar, seria natural esperar que a avaliação da posição real (atitude ou crença) do gestor fosse função da posição expressa no texto, o que de fato se verificou. A hipótese inicial de pesquisa $\left(\mathrm{H}_{1}\right)$ foi confirmada.

A hipótese central de pesquisa $\left(\mathrm{H}_{2}\right)$ é a de que os auditores cometeriam o excesso de correspondência. A posição expressa no texto continuaria a determinar a avaliação da posição real dos gestores, mesmo com o conhecimento de que os gestores não tinham tido liberdade de escolha quanto à posição manifestada no texto. A comparação das médias entre a condição sem liberdade de escolha / texto favorável ao RDC e a condição sem liberdade escolha / texto contrário ao RDC (53,63 vs 28,77; $t=7,70 ; p<0,01$; Wilcoxon, $p<$ $0,01)$ mostra uma diferença estatisticamente significativa entre as médias e confirma a hipótese de pesquisa $\left(\mathrm{H}_{2}\right)$. Mesmo em um contexto de ausência de liberdade de escolha, em que o gestor escreveu um texto cuja posição (a favor ou contra) foi determinada por um dirigente público, os auditores participantes do experimento fizeram inferências de acordo com a posição do texto, sem descontar suficientemente o fato de que o gestor não teve escolha. Esse resultado caracteriza o excesso de correspondência.

A comparação das condições com liberdade de escolha / texto favorável ao RDC e sem liberdade de escolha / texto favorável ao RDC 154,50 vs 53,62; $t=-0,298 ; \quad p=0,767 ; \quad p=0,648$, Wilcoxon) indica uma diferença estatisticamente não significante entre as médias. Este resultado mostra que o excesso de correspondência foi forte o suficiente para neutralizar o impacto da presença ou ausência de liberdade de escolha no julgamento dos auditores em relação a posição do gestor. Em consequência, a hipótese de pesquisa $\left(\mathrm{H}_{3}\right)$ foi confirmada.

A comparação das condições com liberdade de escolha / texto contrário ao RDC e sem liberdade de escolha / texto contrário ao RDC $(28,17$ vs 28,77; $t=-0,219 ; p=0,827 ; p=0,480$, Wilcoxon) indica, igualmente, uma diferença estatisticamente não significante entre as médias. Em consequência, a hipótese de pesquisa $\left(\mathrm{H}_{4}\right)$ foi igualmente confirmada.

A Tabela 2 sumariza o posicionamento dos auditores em relação ao tema do RDC, em cada uma das quatro condições experimentais. Esses dados permitem que se avalie a existência ou não de diferenças significativas entre as posições dos auditores sobre o tema. 


\section{Tabela 2: Médias das posições dos auditores sobre o tema do RDC}

\begin{tabular}{|c|c|c|}
\hline \multirow[b]{2}{*}{ Contexto } & \multicolumn{2}{|c|}{ Posição do texto } \\
\hline & $\begin{array}{l}\text { Texto favorável } \\
\text { ao RDC }\end{array}$ & $\begin{array}{l}\text { Texto } \\
\text { ao RDC }\end{array}$ \\
\hline $\begin{array}{l}\text { Gestor sem liberdade } \\
\text { de escolha }\end{array}$ & $36,25 \quad(n=16)$ & $38,68 \quad(n=22)$ \\
\hline $\begin{array}{l}\text { Gestor com liberdade } \\
\text { de escolha }\end{array}$ & $38,29 \quad(n=24)$ & $(n=23)$ \\
\hline
\end{tabular}

Fonte: Elaborada pelos autores

As médias das posições dos auditores com relação ao tema não são estatisticamente diferentes entre si em cada uma das quatro condições experimentais (qui-quadrado $=0,582 ; p=0,90$; teste de Kruskal-Wallis). A média geral das posições dos auditores foi de 37,77, o que indica uma inclinação a ser contra o tema (uma posição neutra equivaleria a 40). A diferença foi estatisticamente significante com grau de confiança 0,05 ( $n=85, t=-2,164$, $p=0,033)$. $O$ grupo de auditores participantes se mostrou em média contra $o$ tema do Regime Diferenciado de Contratações Públicas - RDC.

\section{LIMITAÇÕES DA PESQUISA}

No que se refere à validade interna do experimento, deve-se registrar a possibilidade de existir uma pressão para que os participantes utilizem o texto recebido no momento de fazer inferências, o que os levaria a utilizá-lo mesmo nos casos em que uma abordagem racional suporia a não utilização. Este seria o caso, por exemplo, de um cenário onde o participante usasse o texto para fazer inferências sobre o autor, no caso em que o autor do texto não teve escolha, por achar que se o texto faz parte do experimento é porque deve ser utilizado. Uma forma de mitigar essa limitação foi o anonimato assegurado aos participantes.

A validade externa deste experimento pode sofrer limitações, tendo em vista que os experimentos foram realizados a partir de uma amostra não probabilística e não intencional, ou seja, regida por critérios de conveniência ou disponibilidade dos inquiridos. Outro fator que poderia comprometer a validade externa é a questão de incentivos. No cotidiano de trabalho, os auditores deparam-se com incentivos associados à remuneração e à preservação de uma reputação profissional.

A literatura internacional evidencia que auditores incorrem, em ambientes experimentais, os vieses observados em experimentos com estudantes. Shields et al (1987) concluíram que os resultados das pesquisas que conduziram são consistentes com pesquisas prévias que indicam que julgamentos de auditores não são menos propensos a vieses do que o julgamento expresso por outros participantes em experimentos de psicologia. Ashton $(1982,1983)$ chegou a conclusões similares. Não obstante essas conclusões, uma limitação decorre do fato de que apesar de as tarefas usadas nesse estudo guardarem relação indireta com o trabalho dos auditores, o ambiente real de auditoria é significativamente mais complexo. 
O exercício do cargo de Auditor Federal de Controle Externo do Tribunal de Contas da União - TCU, área e especialidade Controle Externo, consiste em desenvolver atividades de planejamento, coordenação e execução relativas à fiscalização e ao controle externo da arrecadação e aplicação de recursos da União, bem como da administração desses recursos, examinando a legalidade, legitimidade, economicidade, eficiência e efetividade, em seus aspectos financeiro, orçamentário, contábil, patrimonial e operacional, dos atos daqueles que devam prestar contas ao Tribunal. Tendo em vista que diferentes campos de auditoria podem ter diferentes características, generalizações dos estudos envolvendo outros auditores para o contexto dos auditores do TCU, e vice-versa, não obstante possíveis e potencialmente relevantes, devem ser feitas com ressalvas.

\section{DISCUSSÃO E CONSIDERAÇÕES FINAIS}

Os auditores do TCU participantes deste experimento exercem suas funções profissionais com base no arcabouço jurídico existente, devendo seguir, em relação ao tema de licitações e contratos, a Lei 8666/93, considerada a lei geral de licitações e contratos, bem como todos os normativos mais específicos existentes, como a Lei do Pregão Eletrônico, e eventual legislação referente ao Regime Diferenciado de Contratações Públicas (RDC), por exemplo.

Há, no âmbito dos auditores do TCU, posições diferenciadas em relação ao RDC, como os resultados deste experimento indicam. Ressalta-se, entretanto, que a pergunta central desta pesquisa consistiu na avaliação dos auditores em relação à posição real do gestor sobre o tema, de modo a se verificar a existência do excesso de correspondência. Neste sentido, o resultado da pesquisa evidencia a existência do excesso de correspondência. Os auditores fizeram inferências sobre a posição real de gestores (sobre um tema) com base na posição do texto escrito pelos gestores, mesmo nos casos em que os gestores não tiveram escolha quanto à inclinação e posição do texto.

A Portaria 280/2010 (alterada pela Portaria 168/2011), que trata das Normas de Auditoria do Tribunal de Contas da União, dispõe que é de responsabilidade dos auditores emitir opiniões somente sobre documentos ou situações examinadas, apoiando-se em fatos em evidências. As situações examinadas são as mais diversas, de modo que o auditor, com base nas evidências de que dispõe, emite suas opiniões, materializadas por meios de instruções ou relatórios. As informações coletadas não são, contudo, sempre completamente confiáveis nem perfeitamente preditivas da situação sendo examinada, de modo que algum grau de julgamento terá, com frequência, que ser exercido. Neste processo, o auditor precisa averiguar, da forma mais precisa possível, condutas de diversos agentes e, com frequência, precisa fazer atribuições causais em relação aos atos praticados por gestores. Auditores podem se beneficiar, portanto, de pesquisas que identifiquem a ocorrência, em potencial, de eventuais vieses de julgamento como o excesso de correspondência.

As contribuições deste estudo devem, entretanto, serem ponderadas pelas limitações existentes, mencionadas no texto. A partir destas limitações algumas sugestões para pesquisas futuras parecem se justificar. A inserção de 
variáveis independentes, mormente com relação à inclusão de alguma responsabilidade aos auditores participantes do experimento, pode contribuir para um entendimento maior da eventual diminuição do viés de correspondência num contexto em que haja uma responsabilidade explícita. Não obstante haver estudo sobre o viés de correspondência com a manipulação da variável independente da responsabilidade (TETLOCK, 1985), não se vislumbram estudos utilizando auditores profissionais.

\section{REFERÊNCIAS}

ALICKE, M.; ZERBST, J.; LOSCHIAVO, F. Personal attitudes, constraint magnitude, and correspondence bias. Basic and Applied Social Psychology 18, pp. 211-228, 1996.

ASHTON, R.H. Human information processing in accounting. Sarasota: AAA, 1982.

ASHTON, R.H. Research in audit decision making: Rationale, evidence and implications. Vancouver: Canadian Certified General Accountants' Monograph n. 6, 1983.

BEM, D.J. Self-Perception: An alternative interpretation of cognitive dissonance phenomena. Psychological Review 74, pp. 183-200, 1967

$\mathrm{CHOI}$, I.; NISBETT, R.E. Situational salience and cultural differences in the correspondence bias and the actor-observer bias. Personality and Social Psychology Bulletin 24, pp. 949-960, 1998.

CROXTON, J.S.; MILLER, A.G. Behavioral disconfirmation and the observer bias. Journal of Social Behavior and Personality 2, pp. 145-152, 1987.

GILBERT, D.T.; MALONE, P.S. The correspondence bias. Psychological Bulletin 117 , pp. 21-38, 1995.

HEIDER, F. The psychology of interpersonal relations. New York, Willey, 1958.

HILL, G. A lever psychology through diagrams. Oxford, 2001.

HOGG, M.A.; VAUGHAN, G.M. Social Psychology. Pearson, 2011.

JONES, E.E.; DAVIS, K.E. From acts to dispositions: The attribution process in person perception. In L. Berkwitz, Advances in experimental social psychology vol. 2, pp. 219-266, 1965.

JONES, E.E.; RIGGS, J.M.; QUATTRONE, G. Observer bias in the attitude attribution paradigm: Effect of time and information order. Journal of Personality and Social Psychology 37, pp. 1230-1238, 1979. 
JONES, E.E.; HARRIS, V.A. The attribution of attitudes. Journal of Experimental Social Psychology vol. 3, pp. 1-24, 1967.

JONES, E.E. The rocky road from acts to dispositions. American Psychologist vol. 34, pp. 107-117, 1979.

KELLEY, H.H. Attibution theory in social psychology. In D. Levine, Nebrasca symposium on motivation, Lincoln, University of Nebrasca Press, 1967.

MILLER, A.G.; RORER, L.G. Toward an understanding of the fundamental attribution error: Essay diagnosticity in the attitude attribution paradigm. Journal of Research in Personality vol. 16, pp. 41-59, 1982.

MILLER, A.G.; SCHMIDT, D.; MEYER, C.; COLELLA; A. The perceived value of constrained behavior: Pressures toward biased inference in the attitude attribution paradigm. Social Psychology Quarterly vol. 47, pp. 160-171, 1984.

MILLER, A.G. Constraint and target effects in the attribution of attitudes. Journal of Experimental Social Psychology vol. 12, pp. 325-339, 1976.

NISBETT, R.E.; BORGIDA, E.; CRANDALL, R.; REED, H. Popular induction: Information is not necessarily informative. In Kahneman et al, Judgment under uncertainty: heuristics and biases, Cambridge University Press, 1982.

ROSS, L.; AMABILE, T.M.; STEINMETZ, J.L. Social roles, social control, and biases in social-perception processes. Journal of Personality and Social Psychology 35, pp. 485-494, 1977.

ROSS, L.; ANDERSON, C.A. Shortcomings in the attribution process: On the origins and maintenance of erroneous social assessments. New York: Oxford University Press, pp. 129-152, 1982.

SCHACHTER, S. The interaction of cognitive and physiological determinants of emotional state. In L. Berkowitz (Ed.), Advances in experimental social psychology vol. 1, New York: Academic Press, 1964.

SHANTEAU, J. Cognitive heuristics and biases in behavioral auditing: Review, comments and observations. Accounting Organizations and Society vol. 14, pp. 165-177, 1989.

SHIELDS, M.D.; SOLOMON, I.; WALLER, W.S. Effects of alternative sample space representations on the accuracy of auditors' uncertainty judgments. Accounting, Organization and Society, pp. 375-385, 1987.

SNYDER, M. L.; FRANKEL, A. Observer bias: A stringent test of behavior engulfing the field. Journal of Personality and Social Psychology 34, pp. 857-864, 1976.

SNYDER, M.L.; JONES, E. E. Attitude attribution when behavior is constrained. Journal of Experimental Social Psychology vol. 10, pp. 585-600, 1974. 
TETLOCK, P.E. Accountability: A Social Check on the Fundamental Attribution Error. Social Psychology Quarterly vol. 48, pp. 227-236, 1985.

WEINER, B. A Theory of motivation for Some Classroom Experiences. Journal of Educational Psychology 71, pp. 3-25, 1979.

WEINER, B. (1985). An attributional theory of achievement motivation and emotion. Psychological Review 92, pp. 548-573, 1985. 